\title{
Participant Experiences in the Environmental Determinants of Diabetes in the Young Study: Common Reasons for Withdrawing
}

\author{
Barbro Lernmark, ${ }^{1}$ Kristian Lynch, ${ }^{2}$ Judith Baxter, ${ }^{3,4}$ \\ Roswith Roth, ${ }^{5}$ Tuula Simell, ${ }^{6}$ Laura Smith, ${ }^{2}$ Ulrica Swartling, ${ }^{1}$ \\ Suzanne Bennett Johnson, ${ }^{7}$ and TEDDY Study Group ${ }^{1,2,3,5,6,8,9}$ \\ ${ }^{1}$ Department of Clinical Sciences, Lund University, CRC, Jan Waldenströms Gata 35, Skåne University Hospital (SUS), \\ 20502 Malmö, Sweden \\ ${ }^{2}$ Health Informatics Institute, University of South Florida, 3650 Spectrum Boulevard, Suite 100, Tampa, FL 33612, USA \\ ${ }^{3}$ Barbara Davis Center for Childhood Diabetes, School of Medicine, University of Colorado Denver-AMC, 1775 Aurora Court, \\ Aurora, CO 80045, USA \\ ${ }^{4}$ Colorado School of Public Health, Department of Community and Behavioral Health, University of Colorado Denver-AMC, \\ 13001 E. 17th Place, Aurora, CO 80045, USA \\ ${ }^{5}$ Institute of Diabetes Research, Helmholtz Center Munich and Clinic on the right of Isar, Technical University Munich, \\ Research Group Diabetes e.V., Ingolstaedter Landstrasse 1, 85764 Neuherberg, Germany \\ ${ }^{6}$ Department of Pediatrics, University of Turku, Kinamyllynkatu 4-8, 20100 Turku, Finland \\ ${ }^{7}$ Department of Medical Humanities and Social Sciences, Florida State University College of Medicine, 1115 West Call Street, \\ Tallahassee, FL 32306, USA \\ ${ }^{8}$ Pacific Northwest Diabetes Research Institute, 720 Broadway, Seattle, WA 98122, USA \\ ${ }^{9}$ Center for Biotechnology and Genomic Medicine, Medical College of Georgia, Georgia Regents University, 1120 15th Street, \\ CA-4123, Augusta, GA 30912, USA
}

Correspondence should be addressed to Laura Smith; 1smith5@health.usf.edu

Received 23 January 2015; Accepted 2 May 2015

Academic Editor: Nitin Gupta

Copyright ( 2016 Barbro Lernmark et al. This is an open access article distributed under the Creative Commons Attribution License, which permits unrestricted use, distribution, and reproduction in any medium, provided the original work is properly cited.

Background. To characterize participant reasons for withdrawing from a diabetes focused longitudinal clinical observational trial (TEDDY) during the first three study years. Methods. 8677 children were recruited into the TEDDY study. At participant withdrawal staff recorded any reason parents provided for withdrawal. Reasons were categorized into (1) family characteristics and (2) protocol reasons. Families who informed staff of their withdrawal were classified as active withdrawals (AW); families without a final contact were considered passive withdrawals (PW). Results. Withdrawal was highest during the first study year $(n=1220)$. Most families were AW $(n=1549 ; 73.4 \%)$. PW was more common in the United States $(n=1001 ; 37.8 \%)$ and among young mothers $(p=0.001)$. The most frequent protocol characteristic was blood draw (55\%) and the most common family reason was not having enough time (66\%). The blood draw was more common among female participants; being too busy was more common among males. Both reasons were associated with study satisfaction. Conclusions. Results suggest that, for families of children genetically at risk for diabetes, procedures that can be painful/frightening should be used with caution. Study procedures must also be considered for the demands placed on participants. Study satisfaction should be regularly assessed as an indicator of risk for withdrawal.

\section{Introduction}

The Environmental Determinants of Diabetes in the Young (TEDDY) study is a multicenter longitudinal clinical observational trial studying the natural history of the development of type 1 diabetes (TIDM) in children. Soon after birth, children were tested for HLA conferred genetic risk for T1DM. Children with the highest genetic risk were invited to participate in TEDDY. The purpose of the TEDDY study is to identify environmental factors that trigger autoimmunity and TIDM [1]. 
The success of longitudinal research studies, investigating important factors that contribute to T1DM, like TEDDY, is dependent upon study retention. It is important to investigate what study and psychosocial characteristics prompt families to leave a study in order to (1) implement possible preventive actions to increase retention and (2) design future longitudinal studies for this at-risk T1DM population in ways that enhance study retention. Although this topic is critical for the success of longitudinal trials, the extant literature is somewhat sparse. In fact, only 55\% percent of pediatric trials report refusal or withdrawal reasons based on a recent literature review [2]. Previous work within more varied pediatric populations and interventional studies (e.g., T1DM, asthma, and obesity intervention trials) has suggested that a number of sociodemographic factors (e.g., older child age, minority status, and lower income) and psychological factors (e.g., greater depression and lower quality of life) were related to study withdrawal [3-6]. However, these findings from intervention studies in chronic illness populations may not be fully applicable to the TEDDY at-risk for T1DM population. Further, previous studies have tended to focus on existing characteristics of participants who do not complete a study rather than directly ascertaining reasons for withdrawal from the participants themselves.

A longitudinal study similar to the TEDDY study reported that logistical matters like blood sampling and lack of time were the reasons most often mentioned by families who withdrew [7]. In the TEDDY population, we have reported that characteristics of the study protocol, like blood draws, and family factors, like being too busy, were the primary reasons families did not join the study [8]. Study enrollment was associated with sociodemographic factors such as whether the child had a mother, father, and/or sibling with T1DM (first degree relative (FDR)), had an older mother, was a singleton, or had a sibling already enrolled in the study. Enrollment rates differed between the TEDDY countries, with a larger proportion of parents recruited from the European countries [8].

In other prior works, we identified predictors of withdrawal during the first year (up to the 15 months' visit) of TEDDY among families from the general population (GP) who had no immediate family member with T1DM [9]. Study withdrawal was more common if the mother was young, the father did not participate, or the study child was female. Also, mothers of children who withdrew were more likely to report smoking during pregnancy, abstaining from alcohol, and reducing their work hours or not working at all during pregnancy. Mothers who withdrew were also more likely to fail to complete items on study questionnaires and to underestimate their child's TIDM risk. Among mothers with accurate perceptions of their child's T1DM risk, high maternal anxiety was associated with study withdrawal [9]. This information was used to identify families at high risk for leaving the TEDDY study in the first year; these families were then provided with an intervention to promote retention [10]. While factors associated with withdrawal could be used to screen for families at risk of dropout, the effectiveness of interventions aimed at improving the retention of participants can also be influenced by the families' specific reasons for withdrawing.
Thus, in this study we examined data from all families who left TEDDY (both GP and FDR) during the first three study years, including sociodemographic and psychosocial variables, and their reasons for opting out of the study.

\section{Methods}

2.1. TEDDY Study and Data. The TEDDY study has centers in four countries (Finland, Germany, Sweden, and the United States) and is supported by the National Institutes of Health (NIH). The study protocol includes study visits every three months from 3-4 months of age until the child is four years old and biannually thereafter. The study protocol includes blood draws, nasal swabs, height and weight measurements, and parental interviews where aspects of the child's health are recorded together with different types of life events. At regular intervals TEDDY parents fill out questionnaires with demographic questions, health histories, life events, and parents' worries and anxiety concerning the child's increased genetic risk for T1DM. Parents are also requested to complete food diaries and collect stool samples. Altogether, the TEDDY study protocol is very demanding in length and in terms of the frequency and nature of its components [1].

The collection of cord blood for screening and possible TEDDY enrollment started in September 1, 2004, and ended February 28, 2010. A total of 424,788 children were screened for increased HLA conferred genetic risk for T1DM and 21,589 were HLA eligible [11]. The enrollment rate of families with children at increased genetic risk was $38.4 \%$ from the general population (GP) and $64.8 \%$ from FDR families. The number and proportion of eligible children as well as the number of children enrolled differed both between countries and between GP and FDR families [8].

The earlier a family withdrew from the study, the fewer data points were available. For all children, demographic factors like country, gender, month of birth, FDR/GP status, and mother's age were obtained in connection with the collection of cord blood to determine eligibility for TEDDY. Data for all children enrolled in TEDDY were also available from the questionnaires that each parent completed in connection with the first TEDDY visit. These psychosocial measures contained questions on parents' views on the child's risk for developing diabetes, their worries about that possibility, and their thoughts on having the child tested for genetic T1DM risk. The mother also answered questions on lifestyle factors during pregnancy (smoking and alcohol consumption). For families withdrawing after the first study year, there were additional demographic data collected during the first year of TEDDY, including parents' education, child ethnic minority status, only child status, and household crowding. Psychosocial data were collected repeatedly starting at the 3 and 6 months' visits, at 15 months, at 27 months, and yearly. In the current study, the psychosocial data collected immediately before withdrawal were used. These data are worries (e.g., How often do you worry that your child will get diabetes: never/very often), anxiety (short version of the State-Trait Anxiety Inventory (SAI)) [12], depression (Bradley's Wellbeing Scale) [13], study satisfaction (three correlated questions summed into a satisfaction score: Overall, how do you feel 


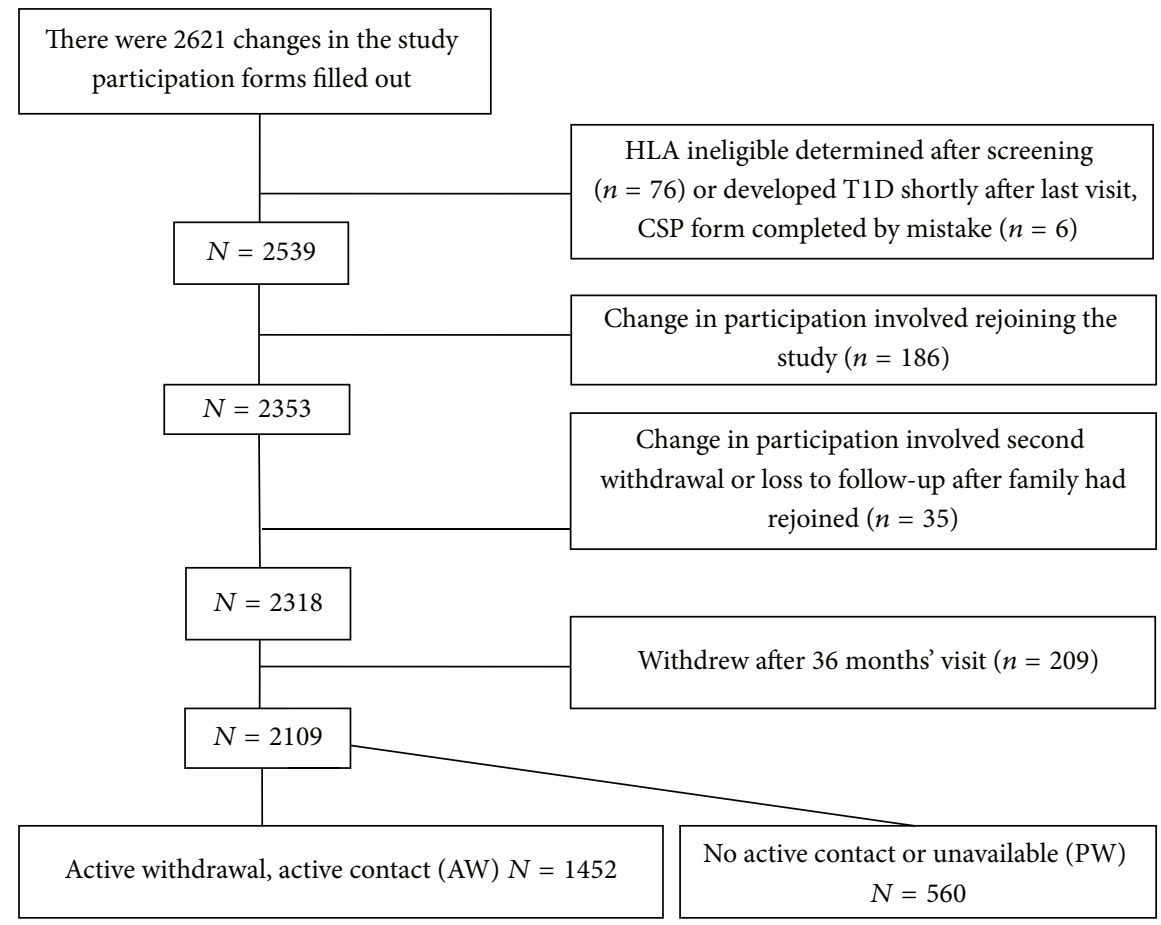

Figure 1: Study population.

about having your child participate in the TEDDY study? Do you think your child's participation in the TEDDY study was a good decision? Would you recommend the TEDDY study to a friend?), and risk perception (Compared to other children do you think your child's risk to develop diabetes is much lower/much higher?).

2.2. Data Collection. When a family withdrew from TEDDY, a Change in Study Participation Form (CSP Form) was filled out by TEDDY staff and any reason the parent gave for leaving the study was recorded. More than one reason could be recorded. If a family did not give a reason for leaving the study this was also noted. The last visit when any data were collected from the family was taken as the time of withdrawal even though the CSP form could be completed at a much later date. For some families, the decision to withdraw from TEDDY was difficult and could span over a long period of time with several cancelled visits and no collection of data before a final decision to leave the study. If a family did not come to the clinic for more than a year despite scheduled visits and did not contribute any data over the course of one year, the family was considered to be a Passive Withdrawal (PW) and a CSP Form was completed. Families that became unavailable and impossible to reach were also PW and were considered TEDDY withdrawals.

2.3. Statistical Analysis. Differences in frequencies between categorical groups were tested by chi-square tests. For continuous variables, differences in means were tested by independent two-sample $t$-tests. Multiple linear regression was used to examine the association of demographic and psychosocial variables with specific common reasons for withdrawing.
Demographic variables available on all subjects were examined first and later psychosocial factors were added. Data from the last questionnaire prior to withdrawal were used to estimate maternal anxiety, risk perception, worry, and study satisfaction. If for any reason there were missing data, information was taken from the last questionnaire available. Univariate and multiple logistic regression models were used to test for significant factors associated with type of withdrawal (PW versus AW). Analyses were performed using SAS 9.2. $p$ values less than 0.05 were considered statistically significant.

\section{Results}

A total of 8677 children were recruited into the TEDDY study. From September 1, 2004, until July 31, 2012, there were 2621 CSP forms filled out. CSP forms from all children who left the study on or before the 3-year visit were selected for analysis. Figure 1 gives an overview of how the study cohort was created. In all, 512 forms were excluded from the study for reasons outlined in the figure, resulting in 2109 CSP forms describing the first time withdrawal of the family from the study. Of these, 1549 forms came from families who told the staff they wanted to withdraw from TEDDY (AW); 90\% gave at least one reason why they opted out. A total of 560 families (26.6\%) did not respond to repeated scheduling attempts for more than a year or became impossible to contact and were withdrawn by the TEDDY staff without any further contact (PW). In Figure 2, the number of AW and PW for the different countries is shown by visit. Overall, study withdrawal was highest during the first year of the study and decreased thereafter and AW was far more common than PW. The United States had the highest frequency of PW $(n=378$; 

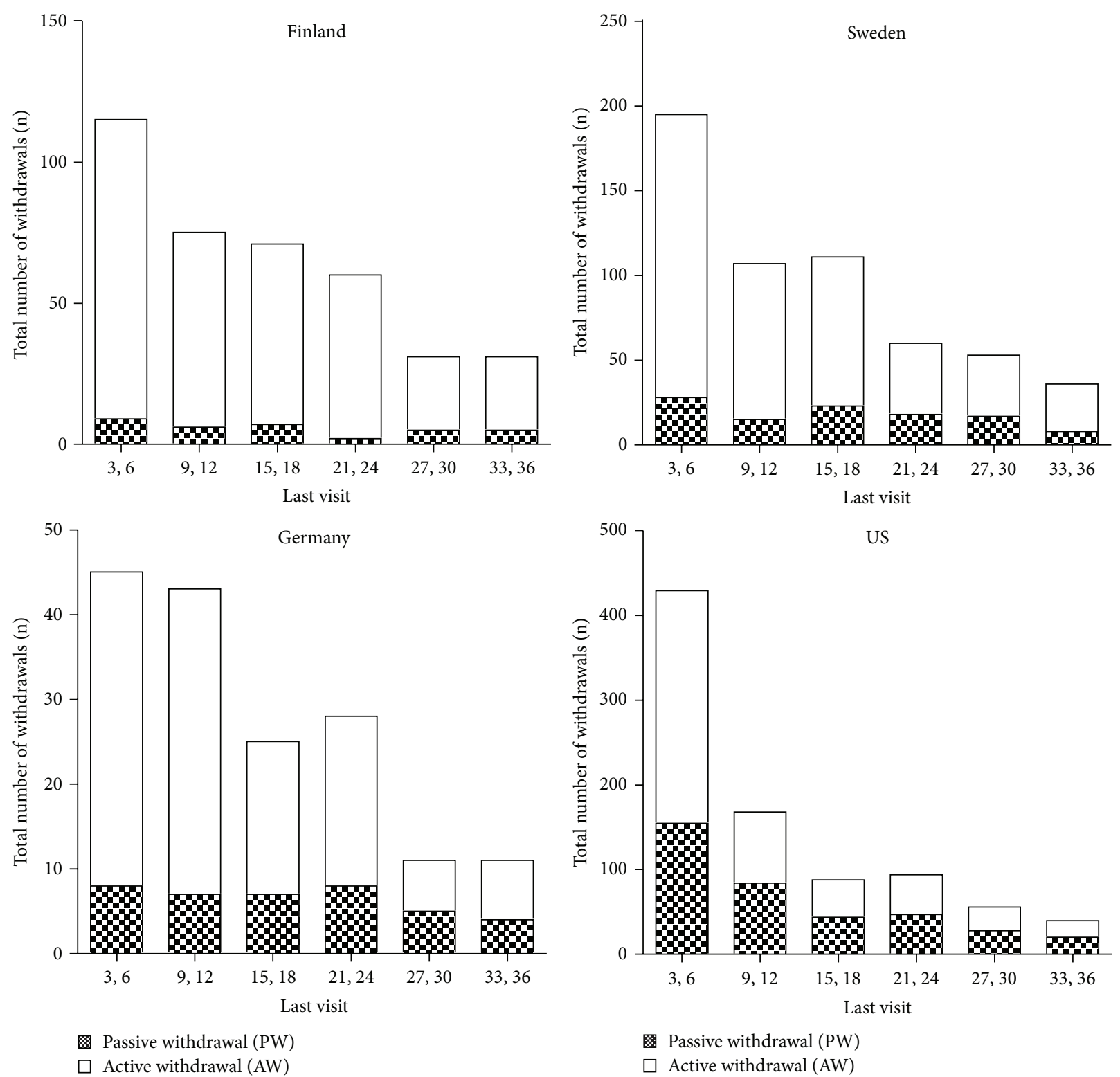

FIGURE 2: Number of withdrawals by age of last visit and by country divided into passive withdrawals (PW) (checked) and active withdrawals (AW) (white).

23.9\%) and the relative proportion of PW increased over time. Finland had the lowest PW rate $(n=34 ; 8.9 \%)$ and it remained low across all study years. In Germany 39 children (23.9\%) and in Sweden 109 children (19.0\%) were classified as PW. There was a significantly increasing trend of PW proportion over the study period in Germany $(p=0.024)$ and Sweden during the three years $(p=0.001)$ even though the number of both PW and AW decreased.

Univariate and multiple regressions were used to identify factors that differentiated between AW and PW. PW were significantly more common in other countries compared to Finland, among young moms, and in older children. In the univariate models, high anxiety, maternal smoking during pregnancy, and lack of father participation in TEDDY were associated with PW. However, these factors did not remain significant in the multivariate model (Table 1).

Table 2 depicts characteristics of the AW by age of the child at the time of withdrawal. In the first half year after enrollment, $24.1 \%$ of the AW were young mothers ( $<25$ years) which was significantly different compared to year 3 when $14.8 \%$ were young mothers. The early AW were also more anxious mothers $(<0.001)$ and mothers more worried about their child developing diabetes $(p=0.003)$ compared to those remaining in the study. There were no significant associations between the accuracy of the mother's T1DM risk perception or study satisfaction and the child's age at withdrawal.

The frequencies of different reasons reported by the AW distributed over visits during the three study years are shown 
TABLE 1: Factors associated with passive withdrawal (PW) versus active withdrawal (AW).

\begin{tabular}{|c|c|c|c|c|c|c|c|c|}
\hline \multirow{2}{*}{ Factors ${ }^{\mathrm{a}}$} & \multirow{2}{*}{$\begin{array}{c}\text { Number } \\
\text { mean }(S D)\end{array}$} & \multicolumn{4}{|c|}{ Univariate } & \multicolumn{3}{|c|}{ Multivariate } \\
\hline & & $\%$ of PW & OR & $95 \% \mathrm{CI}$ & $p$ value & OR & $95 \%$ CI & $p$ value \\
\hline \multicolumn{9}{|l|}{ Country of residence } \\
\hline Finland & 383 & 8.9 & 1.00 & Ref. & & 1.00 & Ref. & \\
\hline Sweden & 562 & 19.4 & 2.47 & $1.64-3.72$ & & 2.86 & $1.85-4.44$ & \\
\hline Germany & 163 & 23.9 & 3.22 & $1.95-5.34$ & & 3.73 & $2.16-6.43$ & \\
\hline US & 1001 & 37.8 & 4.28 & $3.26-9.06$ & $<0.001$ & 6.57 & $4.35-9.93$ & $<0.0011$ \\
\hline \multicolumn{9}{|c|}{ Maternal age at child's birth (years) } \\
\hline Years & $28.9(5.7)$ & & 0.94 & $0.93-0.96$ & $<0.001$ & 0.95 & $0.93-0.97$ & $<0.001$ \\
\hline$<29$ years & 1016 & 32.0 & & & & & & \\
\hline$\geq 29$ years & 1093 & 21.5 & & & & & & \\
\hline \multicolumn{9}{|c|}{ Child's age of withdrawal (years) } \\
\hline Years & $1.16(0.80)$ & & 1.12 & $0.99-1.25$ & 0.08 & 1.33 & $1.16-1.52$ & $<0.001$ \\
\hline$<1.16$ years & 1231 & 25.8 & & & & & & \\
\hline$\geq 1.16$ years & 878 & 27.6 & & & & & & \\
\hline \multicolumn{9}{|l|}{ Gender } \\
\hline Female & 1094 & 25.9 & 1.00 & Ref. & & 1.00 & Ref. & \\
\hline Male & 1015 & 27.3 & 1.08 & $0.88-1.31$ & 0.46 & 1.10 & $0.88-1.36$ & 0.40 \\
\hline \multicolumn{9}{|l|}{$\mathrm{FDR}^{\mathrm{a}}$} \\
\hline No & 1957 & 26.8 & 1.00 & Ref. & & 1.00 & Ref. & \\
\hline Yes & 152 & 23.7 & 0.85 & $0.57-1.25$ & 0.41 & 0.95 & $0.62-1.47$ & 0.81 \\
\hline \multicolumn{9}{|l|}{ Smoking during pregnancy } \\
\hline No & 1556 & 25.2 & 1.00 & Ref. & & 1.00 & Ref. & \\
\hline Yes & 415 & 30.4 & 1.30 & $1.02-1.64$ & 0.03 & 1.31 & $1.00-1.72$ & 0.05 \\
\hline \multicolumn{9}{|l|}{ Alcohol 3rd trimester } \\
\hline No & 1713 & 26.1 & 1.00 & Ref. & & 1.00 & Ref. & \\
\hline Yes & 289 & 27.3 & 1.07 & $0.81-1.41$ & 0.66 & 1.16 & $0.85-1.60$ & 0.35 \\
\hline \multicolumn{9}{|l|}{ Worked during pregnancy } \\
\hline No or reduced hours & 1184 & 26.6 & 1.00 & Ref. & & 1.00 & Ref. & \\
\hline Yes or increased hours & 819 & 25.8 & 0.96 & $0.78-1.17$ & 0.67 & 0.92 & $0.74-1.15$ & 0.45 \\
\hline \multicolumn{9}{|l|}{ High anxiety (SAI > 48) } \\
\hline Score & $40.9(10.7)$ & & 1.02 & $1.01-1.03$ & $<0.001$ & 1.00 & $0.99-1.01$ & 0.80 \\
\hline$<40.9$ score & 1059 & 22.6 & & & & & & \\
\hline$\geq 40.9$ score & 921 & 29.4 & & & & & & \\
\hline \multicolumn{9}{|l|}{ Risk perception } \\
\hline Underestimate & 901 & 27.3 & 1.00 & Ref. & & 1.00 & Ref. & \\
\hline Accurate & 1097 & 25.2 & 0.90 & $0.73-1.09$ & 0.28 & 0.99 & $0.80-1.23$ & 0.93 \\
\hline \multicolumn{9}{|l|}{ Father not active $(3 \mathrm{mo})^{\mathrm{b}}$} \\
\hline No & 1807 & 25.0 & 1.00 & Ref. & & 1.00 & Ref. & \\
\hline Yes & 302 & 36.1 & 1.70 & $1.31-2.20$ & $<0.001$ & 1.27 & $0.90-1.78$ & 0.17 \\
\hline
\end{tabular}


TABLE 2: Active withdrawals by child's age of withdrawal and demographic factors, maternal psychosocial factors, and maternal study satisfaction.

\begin{tabular}{|c|c|c|c|c|c|c|}
\hline Factors & $\begin{array}{c}\text { All } \\
3-36 \mathrm{~m} \\
(N)\end{array}$ & $\begin{array}{c}\text { Year } 1 \\
3-6 \mathrm{~m} \\
N(\text { row } \%) \text { or } \\
\text { mean }(\mathrm{SD})\end{array}$ & $\begin{array}{c}\text { Year } 1 \\
9-12 \mathrm{~m} \\
N(\text { row } \%) \text { or } \\
\text { mean }(\mathrm{SD})\end{array}$ & $\begin{array}{c}\text { Year } 2 \\
15-24 \mathrm{~m} \\
N(\text { row } \%) \text { or } \\
\text { mean }(\mathrm{SD})\end{array}$ & $\begin{array}{c}\text { Year } 3 \\
27-36 \mathrm{~m} \\
N(\text { row } \%) \text { or } \\
\text { mean }(\mathrm{SD})\end{array}$ & $p$ value \\
\hline Number of active withdrawals & 1549 & $584(37.7)$ & $324(20.9)$ & $431(27.8)$ & $210(13.6)$ & \\
\hline \multicolumn{7}{|l|}{ Country of residence } \\
\hline Finland & 349 & $106(30.4)$ & $69(19.8)$ & $122(35.0)$ & $52(14.9)$ & \\
\hline Sweden & 453 & $167(36.9)$ & $92(20.3)$ & $130(28.7)$ & $64(14.1)$ & \\
\hline Germany & 124 & $37(29.8)$ & $36(29.0)$ & $38(30.6)$ & $13(10.5)$ & \\
\hline US & 623 & $274(44.0)$ & $127(20.4)$ & $141(22.6)$ & $81(13.0)$ & $<0.001$ \\
\hline \multicolumn{7}{|l|}{ Gender } \\
\hline Female & 811 & $323(39.8)$ & $159(19.6)$ & $232(28.6)$ & $97(12.0)$ & \\
\hline Male & 738 & $261(35.4)$ & $165(22.4)$ & $199(27.0)$ & $113(15.3)$ & 0.07 \\
\hline \multicolumn{7}{|l|}{ First degree relative with T1D } \\
\hline No & 1433 & $534(37.3)$ & $302(21.1)$ & $406(28.3)$ & $91(13.3)$ & \\
\hline Yes & 116 & $50(43.1)$ & $22(19.0)$ & $25(21.6)$ & $19(16.4)$ & 0.30 \\
\hline \multicolumn{7}{|l|}{ Maternal age at child's birth } \\
\hline years & $29.4(5.6)$ & $28.9(5.8)$ & $29.0(5.2)$ & $29.6(5.5)$ & $30.9(5.5)$ & $<0.001$ \\
\hline \multicolumn{7}{|c|}{ Highly anxious at last visit $(\mathrm{SAI}>48)^{\mathrm{a}}$} \\
\hline No & 1241 & $413(33.3)$ & $259(20.9)$ & $375(30.5)$ & $191(15.4)$ & \\
\hline Yes & 229 & $116(50.7)$ & $55(24.0)$ & 45 (19.7) & $13(5.7)$ & $<0.001$ \\
\hline \multicolumn{7}{|c|}{ Worry about diabetes at last visit ${ }^{\mathrm{a}, \mathrm{b}}$} \\
\hline Never or rarely & 706 & $104(14.7)$ & $166(23.5)$ & $290(41.4)$ & $144(20.4)$ & \\
\hline Sometimes or very often & 344 & $56(16.3)$ & $114(33.1)$ & $113(33.4)$ & $59(17.2)$ & 0.004 \\
\hline \multicolumn{7}{|l|}{ Risk perception at last visit $^{\mathrm{a}}$} \\
\hline Underestimate & 692 & $247(35.7)$ & $147(21.2)$ & $207(30.1)$ & $90(13.0)$ & \\
\hline Accurate & 783 & $283(36.1)$ & $170(21.7)$ & $213(27.5)$ & $115(14.7)$ & 0.63 \\
\hline \multicolumn{7}{|l|}{ Study satisfaction at last visit ${ }^{\mathrm{a}, \mathrm{b}}$} \\
\hline Very satisfied & 276 & $38(13.8)$ & $77(27.9)$ & $108(39.1)$ & $53(19.2)$ & \\
\hline Satisfied & 289 & $44(15.2)$ & $87(30.1)$ & $99(34.3)$ & $59(20.4)$ & \\
\hline Somewhat satisfied & 274 & $39(14.2)$ & $71(25.9)$ & $115(42.0)$ & $49(17.9)$ & \\
\hline Neutral or dissatisfied & 208 & $38(18.3)$ & $44(21.2)$ & $84(40.4)$ & $42(20.2)$ & 0.47 \\
\hline
\end{tabular}

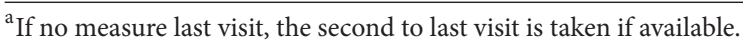

${ }^{\mathrm{b}}$ Study satisfaction and worry about diabetes are not asked in the first questionnaires so there are fewer available answers at 3 and 6 months.

in Table 3. The different reasons are grouped into "protocol characteristics" or "family factors." The two reasons most frequently given for leaving TEDDY were concerns about the blood draw ( $n=359 ; 55 \%$ of all protocol characteristics) and being too busy/not having enough time $(n=587 ; 66.6 \%$ of all family factors). Other frequently mentioned protocol characteristics included the following: the protocol is too demanding, transportation difficulties, and the frequency of visits. Among the family factors, feeling overwhelmed/being too stressed is the second most common reason given $(n=$ $206,23.4 \%)$. Having concerns about the blood draw was more often mentioned for older children $(p=0.039)$, not wanting to be reminded of the child's risk was significantly more often reported as a reason for withdrawal during the first visits $(p=$ 0.003 ), and being too busy/not having enough time was more often reported in the later visits $(p=0.037)$. During the study period, $11 \%$ ( $n=97$ ) of the families cited moving out of the area as a reason for opting out. A total of 165 families (10.7\%) did not want to give a reason for leaving or only wanted to wait and see what might happen.

The result of multiple regressions examining demographic factors in all AW subjects for the two most often mentioned reasons for withdrawal (concerns about blood draw and being too busy) is presented in Table 4. German and US mothers were more likely to report the blood draw as the reason for leaving TEDDY compared to Finland and Sweden. Also, the blood draw was mentioned more often as the child got older and if the child was a girl. Being too busy was given as the reason for leaving TEDDY most often among Swedish mothers and least often among German mothers. This reason was more common in families with an older TEDDY child and if the child was a boy. 
TABLE 3: Frequency of common reasons for withdrawing from the TEDDY study during the first three study years. Percentages for reasons mentioned more frequently are shown.

\begin{tabular}{|c|c|c|c|c|c|c|}
\hline \multirow{4}{*}{ Withdrawals } & \multicolumn{6}{|c|}{ Last visit before withdrawal (month) } \\
\hline & \multirow{3}{*}{$\begin{array}{c}\text { Year } 1 \\
3-6 \mathrm{~m} \\
N(\text { row \%) }\end{array}$} & \multirow{3}{*}{$\begin{array}{c}\text { Year } 1 \\
\text { 9-12 m } \\
N \text { (row \%) }\end{array}$} & \multirow{3}{*}{$\begin{array}{c}\text { Year } 2 \\
15-24 \mathrm{~m} \\
N(\text { row \%) }\end{array}$} & \multirow{3}{*}{$\begin{array}{c}\text { Year } 3 \\
27-36 \mathrm{~m} \\
N(\text { row \%) }\end{array}$} & \multirow{2}{*}{\multicolumn{2}{|c|}{$\begin{array}{c}\text { All } \\
3-36 \mathrm{~m}\end{array}$}} \\
\hline & & & & & & \\
\hline & & & & & $N$ & $\%$ \\
\hline Active withdrawals (AW) & $584(37.7)$ & $324(20.9)$ & $431(27.8)$ & $210(13.6)$ & 1549 & 73.4 \\
\hline \multicolumn{7}{|l|}{ Reasons for withdrawal } \\
\hline Protocol characteristics & $244(37.4)$ & $128(19.6)$ & $195(29.9)$ & $86(13.2)$ & 653 & 100 \\
\hline Concerns about blood draw & $124(34.5)$ & $63(17.5)$ & $112(31.2)$ & $60(16.7)$ & 359 & $55.0^{\mathrm{a}}$ \\
\hline Protocol too demanding & $68(40.0)$ & $41(24.1)$ & $43(25.3)$ & $18(10.6)$ & 170 & $26.0^{\mathrm{a}}$ \\
\hline Transportation difficulties & $44(41.1)$ & $21(19.6)$ & $35(32.7)$ & $7(6.5)$ & 107 & 16.4 \\
\hline Concerns about frequency of visits & $40(39.2)$ & $20(19.6)$ & $33(32.4)$ & $9(8.8)$ & 102 & 15.6 \\
\hline Concerns about stool samples & 14 & 9 & 13 & 7 & 43 & 6.6 \\
\hline Concerns about questionnaires & 15 & 8 & 10 & 4 & 37 & 5.7 \\
\hline Food diaries too troublesome & 12 & 1 & 2 & 1 & 34 & 5.2 \\
\hline Do not want to be reminded of risk & 19 & 6 & 5 & 1 & 31 & 4.7 \\
\hline Duration of study is too long & 1 & 3 & 5 & 1 & 10 & 1.5 \\
\hline No treatment to prevent offered & 3 & 1 & 2 & 1 & 7 & 1.1 \\
\hline Worried about privacy & 1 & 1 & 0 & 0 & 2 & - \\
\hline Worried about loss of insurance & 3 & 0 & 0 & 0 & 3 & - \\
\hline Other protocol characteristics & 2 & 3 & 5 & 2 & 12 & 1.8 \\
\hline Family factors & $279(35.6)$ & $162(20.7)$ & $231(29.5)$ & $112(14.3)$ & 784 & 100 \\
\hline Too busy/not enough time & $187(31.9)$ & $134(22.8)$ & $185(31.5)$ & $81(13.8)$ & 587 & $66.6^{\mathrm{a}}$ \\
\hline Feeling overwhelmed/stressed & $82(39.8)$ & $40(19.4)$ & $58(28.2)$ & $26(12.6)$ & 206 & 23.4 \\
\hline Moving out of the study area & $33(30.4)$ & $23(23.7)$ & $22(22.7)$ & $19(19.6)$ & 97 & 11.0 \\
\hline Child medical/behavioral problems & $29(40.3)$ & $16(22.2)$ & $16(22.7)$ & $11(19.6)$ & 72 & 8.2 \\
\hline Family member emotional problems & 15 & 9 & 18 & 10 & 52 & 5.9 \\
\hline Does not want to be in research & 9 & 3 & 8 & 5 & 25 & 2.8 \\
\hline Family member does not agree to participate & 8 & 0 & 5 & 4 & 17 & 1.9 \\
\hline Family member in another study & 1 & 0 & 2 & 0 & 3 & - \\
\hline Subject already in another study & 0 & 1 & 0 & 0 & 1 & - \\
\hline Fam. health care provider not recommended & 1 & 0 & 0 & 0 & 1 & - \\
\hline Language barrier & 1 & 0 & 0 & 0 & 1 & - \\
\hline Other family factors & 4 & 2 & 4 & 3 & 13 & 1.5 \\
\hline $\begin{array}{l}\text { Active contact made but no reason given or } \\
\text { wants to wait and see }\end{array}$ & $70(42.4)$ & $28(17.0)$ & $42(25.4)$ & $25(15.2)$ & 165 & 10.7 \\
\hline
\end{tabular}

${ }^{\mathrm{a}}$ Significant difference between age groups: concerns about blood draw $(p=0.039)$, do not want to be reminded of risk $(p=0.003)$, and too busy/not enough time $(p=0.037)$.

Maternal smoking during pregnancy, mother working during pregnancy, maternal alcohol consumption during pregnancy, father participation in TEDDY, and whether the TEDDY child was a FDR or from the GP were not associated with either reason for leaving TEDDY.

In Table 5, two logistic regressions explore maternal psychosocial factors in relation to the two most frequently mentioned factors for withdrawing, concerns about blood draw and being too busy. The regressions are adjusted for country of residence, maternal age, age of child at study withdrawal, and gender. The results show that concerns about blood draw were associated with the mother's study satisfaction both at 6 months and at the last visit before withdrawal. At both 6 months and the last visit, mothers 
TABLE 4: Multiple logistic regression examining demographic factors in relation to (a) concerns about blood or (b) being too busy as a reason for withdrawing among those who actively withdrew.

\begin{tabular}{|c|c|c|c|c|c|c|}
\hline \multirow{3}{*}{ Factors at enrollment } & \multicolumn{6}{|c|}{ Demographic measures in relation to concerns about blood draw and being too busy $(n=1549)$} \\
\hline & \multicolumn{3}{|c|}{ (a) Concerns about blood draw } & \multicolumn{3}{|c|}{ (b) Being too busy } \\
\hline & OR & $95 \%$ CI & $p$ value & OR & 95\% CI & $p$ value \\
\hline \multicolumn{7}{|l|}{ Country of residence } \\
\hline Finland & 1.00 & Ref. & & 1.00 & Ref. & \\
\hline Sweden & 1.33 & $0.91-1.93$ & & 1.47 & $1.10-1.96$ & \\
\hline US & 1.72 & $1.21-2.43$ & & 0.83 & $0.63-1.09$ & \\
\hline Germany & 7.80 & $4.89-12.4$ & $<0.001$ & 0.48 & $0.30-0.77$ & $<0.001$ \\
\hline \multicolumn{7}{|c|}{ Maternal age at child's birth (yrs) } \\
\hline Years & 1.05 & $1.02-1.07$ & $<0.001$ & 1.00 & $0.98-1.01$ & 0.62 \\
\hline \multicolumn{7}{|c|}{ Child's age of withdrawal (months) } \\
\hline Months & 1.20 & $1.03-1.40$ & 0.02 & 1.15 & $1.01-1.31$ & 0.04 \\
\hline \multicolumn{7}{|l|}{ Gender } \\
\hline Male & 1.00 & Ref. & & 1.00 & Ref. & \\
\hline Female & 1.44 & $1.12-1.85$ & 0.004 & 0.78 & $0.63-0.96$ & 0.02 \\
\hline
\end{tabular}

Note: FDR/GP status, smoking during pregnancy, working during pregnancy, alcohol consumption during pregnancy, and dad's participation in TEDDY were not associated with either concerns about blood draw or being too busy.

who reported less satisfaction with TEDDY were more likely to report concerns about the blood draw as the reason for leaving TEDDY. The relationship between study satisfaction and mothers' report of being too busy as the reason to leave TEDDY was less clear. No other psychosocial factors (maternal anxiety or mother's risk perception) showed an association with the two most common reasons for leaving the TEDDY study.

\section{Discussion}

The TEDDY study, which seeks to identify factors associated with the development of T1DM, has a demanding protocol for both the children and their parents. The study is also longitudinal with four visits to a TEDDY clinic each year until the child is four years of age and biannually thereafter until the child is fifteen years of age. After 8 years, $72.2 \%$ of the recruited children are still participating in the study. The majority of families who left gave a reason for leaving. PW was more common among the US participants. Being a large country with a diverse population, it is more difficult to track people compared to the European countries. We previously reported that U.S. families often failed to respond to phone messages or letters inviting them to join TEDDY [8], constituting passive refusal, which is similar to PW.

Finland had the lowest number of PW and similar numbers over the years, while the proportion of PW in Germany and Sweden tended to increase during the three study years even though the total number of withdrawals decreased significantly. Some study sites may keep a TEDDY participant as "active" in TEDDY despite multiple missed visits. After getting to know TEDDY staff over many months some families may have difficulty directly telling staff that they are leaving the study and may instead just "no-show." Differences between study centers in how families are managed might develop over time and this is a weakness of the current results reported. However, it is difficult for a large study like TEDDY to systematically define how staff uniformly manage study families over many years.

Sociodemographic factors also related to study withdrawal. PW mothers were younger and more likely to smoke during pregnancy than those retained in the study. In the univariate analysis, lack of father participation in TEDDY was associated with PW but this effect was not statistically significant in the multivariate model. In previous work, we found that lack of father participation was an important predictor of study withdrawal in the first year of TEDDY [9]. Father involvement in a study may be a more important determinant of whether a family stays in a study or withdraws; it may not predict whether the withdrawal is active or passive.

Logistical aspects of the study were found to be common reasons for withdrawal. Even though TEDDY staff is very skilled, drawing blood from a small child can be very challenging and cause unpleasant experiences both for the child and the parent. Other studies have reported that blood draws can be an obstacle for study participation and a reason for opting out [7]. Reporting the blood draw as a reason for leaving TEDDY was more common later in the study than in the early phase. All blood draws are done after application of dermal anesthetics so a baby might react less than a slightly older child who might have learned to fear the blood draw. This observation has been verified by Swedish TEDDY nurses who conducted a parent survey of the child's reaction to the blood draw. In fact, parents tended to rate stronger reactions in older children (personal communication).

Being too busy and not having time to do the TEDDY tasks was the most frequently mentioned reason for leaving the study. Being stressed and feeling overwhelmed was 
TABLE 5: Logistic regression examining maternal psychosocial factors in relation to (a) concerns about blood draw or (b) being too busy as a reason for withdrawing after adjusting for country of residence, maternal age, child's age at withdrawal, and gender (see Table 4).

\begin{tabular}{|c|c|c|c|c|c|c|}
\hline \multirow{3}{*}{ Psychosocial factors } & \multicolumn{6}{|c|}{$\begin{array}{l}\text { Psychosocial measures in relation to concerns about blood and being too busy after adjusting for } \\
\text { demographic factors }(n \sim 1031)\end{array}$} \\
\hline & \multicolumn{3}{|c|}{ (a) Concerns about blood draw } & \multicolumn{3}{|c|}{ (b) Being too busy } \\
\hline & OR & $95 \% \mathrm{CI}$ & $p$ value & OR & $95 \% \mathrm{CI}$ & $p$ value \\
\hline \multicolumn{7}{|c|}{ Maternal high anxiety $(\mathrm{SAI}>48)$} \\
\hline Score & 1.00 & $0.98-1.01$ & 0.42 & 0.99 & $0.98-1.00$ & 0.09 \\
\hline \multicolumn{7}{|l|}{ Mother's risk perception } \\
\hline Underestimate & 1.00 & Ref. & & 1.00 & Ref. & \\
\hline Accurate & 1.01 & $0.74-1.38$ & 0.95 & 0.91 & $0.70-1.18$ & 0.49 \\
\hline \multicolumn{7}{|l|}{ Study satisfaction (6 mo) } \\
\hline Very satisfied & 1.00 & Ref. & & 1.00 & Ref. & \\
\hline Satisfied & 1.38 & $0.89-2.15$ & & 1.24 & $0.88-1.74$ & \\
\hline Somewhat satisfied & 1.80 & $1.16-2.78$ & & 1.80 & $1.27-2.59$ & \\
\hline Neutral or dissatisfied & 2.73 & $1.68-4.42$ & $<0.001$ & 1.11 & $0.73-1.69$ & 0.007 \\
\hline \multicolumn{7}{|l|}{ Study satisfaction (last visit) } \\
\hline Very satisfied & 1.00 & Ref. & & 1.00 & Ref. & \\
\hline Satisfied & 1.57 & $0.99-2.49$ & & 1.19 & $0.84-1.69$ & \\
\hline Somewhat satisfied & 2.54 & $1.61-4.03$ & & 1.43 & $1.00-2.05$ & \\
\hline Neutral or dissatisfied & 2.64 & $1.62-4.31$ & $<0.001$ & 1.33 & $0.89-1.97$ & 0.252 \\
\hline
\end{tabular}

another important reason for not participating anymore. Being busy was significantly more often mentioned as a reason for withdrawal at the later study visits. It may be that when a baby is born, the mother is often home caring for the baby and may not experience the TEDDY tasks as burdensome, compared to later when she may return to work. Also, some TEDDY tasks are easier to complete when the child is a baby like collecting stool samples or doing a 3-day food diary. Also, being in the beginning of a study may give participants a feeling of curiosity and enthusiasm, something that may disappear as the study seems less novel to families.

Psychological reasons also played a role in withdrawal for some families, particularly early in the study. Mothers in families who withdrew early, after the first or second TEDDY visit, appeared to be more anxious and worried about their child getting diabetes compared to mothers in families leaving the study at 9 months or later. This is underscored by the observation that mothers who reported that they did not want to be reminded of the child's risk of T1DM as a reason for withdrawal often left TEDDY after the first two visits.

The two most important factors mentioned as reasons for withdrawal (blood draw and being too busy) were each analyzed in separate regression models, first in relation to demographic factors and in a second model in relation to maternal psychological factors and study satisfaction. Reporting the blood draw as a reason for withdrawal was more common if the child was a girl while stating that the family was too busy to participate was more common if the child was a boy. A study on infant pain response following immunization injection demonstrated that parental behavior has a key role in influencing how infants respond to painful procedures with differences between female and male infants
[14]. We can only speculate that parents may be more sensitive to the possible discomfort of the blood draw in girls than in boys; boys are often expected to be braver than girls. Another study found that girls' pain threshold is lower than that of boys, at least for slightly older children compared to the TEDDY children in our study [15]. This could indicate that the reaction of girls to the blood draw might be stronger than that of the boys and therefore the parents might be more prone to opt out when the child is a girl even when the child is younger.

Why being too busy was more often mentioned when the child was a boy is harder to explain. Sometimes boys are more physically active and this may create more problems for parents in collecting TEDDY samples and data in preparation for the visit. It may also mean that boys are more likely to openly protest going to the TEDDY clinic. All this taken together might give parents a feeling of not having time and being too busy. In the current study, parents who gave the blood draw as a reason for leaving often expressed lower satisfaction with the study both at 6 months, when this was first assessed in TEDDY, and in the survey completed before opting out. It is likely that difficulties with the blood draw were seen early in the study, sometimes continued, and resulted in lower satisfaction with the TEDDY experience and ultimately withdrawal from the study.

In a prior study exploring reasons of why parents stay in TEDDY, having someone watching the child for development of T1DM was the most often mentioned reason. Among the minority of parents who had considered leaving the study, the blood draw, being too busy/not having enough time, a demanding protocol, and food diaries were the most frequently reported reasons for considering leaving [16]. 
These results are in line with what was found in the present study.

In this study, reasons for withdrawal were obtained by the TEDDY staff via interview when the parents decided to leave TEDDY, while our prior published work collected this information by questionnaire [16]. Therefore, the method of obtaining this data does not seem to be important as the results were similar. What is lacking is a more in-depth explanation of why parents are too busy and do not have time to remain in TEDDY. Retention and compliance in a longitudinal study like TEDDY are critical for the success of the study so detailed information about why families leave is important for developing strategies for improving study retention.

\section{Conclusion}

Results from this study suggest some significant factors that should be taken into account to counteract opting out in longitudinal studies focusing on a population at genetic risk for T1DM like TEDDY. Psychological factors clearly play a role in early withdrawal and thus early in the study it is important to record and pay attention to parents' anxieties and worries and to implement procedures that may reduce or address these challenges. Also, young mothers, particularly if the father is not fully present, are at early risk for leaving the study and may need extra attention. Procedures that can be experienced as painful and frightening, like a venous blood draw, need to be used with great caution and all ways to facilitate obtaining the specimen need to be considered. It is important for researchers to carefully think through all components in the study that might increase the demands on the participants and it is important to avoid overburdening families, which may increase the risk of withdrawal. Regular investigations of the subjects' satisfaction with the study can give important information on how the study subjects are experiencing their participation and can predict withdrawal.

\section{Appendix}

\section{The TEDDY Study Group}

Colorado Clinical Center. Marian Rewers, M.D., Ph.D., PI (Ancillary Studies, Human Subjects/Publicity/Publications, Immune Markers, Infectious Agents, Quality Assurance, Steering), Kimberly Bautista (Study Coordinators), Judith Baxter (Psychosocial, Quality Assurance, Study Coordinators, Quality Assurance Subcommittee on Data Quality), Ruth Bedoy (Diet), Daniel Felipe-Morales, Brigitte Frohnert, M.D., and Patricia Gesualdo (Diet, Infectious Agents, Study Coordinators, Clinical Implementation, Quality Assurance Subcommittee on Data Quality), Michelle Hoffman (Study Coordinators, Celiac Disease, Clinical Implementation), Rachel Karban (Study Coordinators), Edwin Liu, M.D. (Celiac Disease), Jill Norris, Ph.D. (Diet, Genetics, Study Coordinators), Adela Samper-Imaz and Andrea Steck, M.D. (Genetics, Clinical Implementation), Kathleen Waugh (Infectious Agents, Laboratory Implementation, Study Coordinators, Quality Assurance Subcommittee on Data Quality), and Hali Wright (Study Coordinators). University of Colorado,
Anschutz Medical Campus, Barbara Davis Center for Childhood Diabetes.

Georgia/Florida Clinical Center. Jin-Xiong She, Ph.D., PI (Ancillary Studies, Genetics, Human Subjects/Publicity/Publications, Steering, Jinfiniti Biosciences LLC, Augusta, GA), Desmond Schatz, M.D. (University of Florida, Human Subjects/Publicity/Publications, Immune Markers, Laboratory Implementation, Maternal Studies), Diane Hopkins (Study Coordinators), Leigh Steed (Study Coordinators, Celiac Disease, Clinical Implementation, Quality Assurance Subcommittee on Data Quality), Jamie Thomas (University of Florida, Infectious Agents, Study Coordinators), Katherine Silvis (Diet), Michael Haller, M.D. (University of Florida, Clinical Implementation), Meena Shankar (University of Florida, Diet), Eleni Sheehan (University of Florida), Melissa Gardiner, Richard McIndoe, Ph.D., Haitao Liu, M.D. (Jinfiniti Biosciences LLC, Augusta, GA), John Nechtman (Jinfiniti Biosciences LLC, Augusta, GA), and Ashok Sharma, Joshua Williams, Gabriela Foghis, and Stephen W. Anderson, M.D. (Pediatric Endocrine Associates, Atlanta, GA). Medical College of Georgia, Georgia Regents University.

Germany Clinical Center. Anette G. Ziegler, M.D., PI (Ancillary Studies, Genetics, Human Subjects/Publicity/Publications, Steering), Andreas Beyerlein, Ph.D. (Diet), Ezio Bonifacio, Ph.D. (Center for Regenerative Therapies, TU Dresden, Immune Markers), Michael Hummel, M.D. (Celiac Disease), Sandra Hummel, Ph.D. (Diet), Kristina Foterek (Research Institute for Child Nutrition, Dortmund, Diet), Mathilde Kersting, Ph.D. (Research Institute for Child Nutrition, Dortmund, Diet), Annette Knopff (Laboratory Implementation), Sibylle Koletzko, M.D. (Dr. von Hauner Children's Hospital, Department of Gastroenterology, Ludwig Maximillians University Munich, Celiac Disease), Claudia Peplow (Study Coordinators), Roswith Roth, Ph.D. (Psychosocial), Joanna Stock (Psychosocial, Study Coordinators), Elisabeth Strauss (Study Coordinators), Katharina Warncke, M.D. (Clinical Implementation), and Christiane Winkler, Ph.D. (Diet, Study Coordinators, Quality Assurance Subcommittee on Data Quality). Forschergruppe Diabetes e.V. and Institute of Diabetes Research, Helmholtz Zentrum München, and Klinikum rechts der Isar, Technische Universität München.

Finland Clinical Center. Jorma Toppari, M.D., Ph.D., PI (University of Turku, Turku University Hospital, Hospital District of Southwest Finland, Ancillary Studies, Human Subjects/Publicity/Publications, Steering, Clinical Implementation), Olli G. Simell, M.D., Ph.D., PI (University of Turku, Turku University Hospital, Hospital District of Southwest Finland, Ancillary Studies, Human Subjects/Publicity/Publications, Steering, Celiac Disease), Annika Adamsson, Ph.D. (Turku University Hospital, Hospital District of Southwest Finland, Study Coordinators), Heikki Hyöty, M.D., Ph.D. (University of Tampere, Tampere University Hospital, Infectious Agents), Jorma Ilonen, M.D., Ph.D. (University of Turku, University of Kuopio, Genetics), Miia Kähönen (University of Oulu, Oulu University Hospital), 
Mikael Knip, M.D., Ph.D. (University of Tampere, Tampere University Hospital, Immune Markers), Annika Koivu (University of Turku, Turku University Hospital, Hospital District of Southwest Finland), Mirva Koreasalo (University of Tampere, Tampere University Hospital, National Institute for Health and Welfare, Finland, Diet), Kalle Kurppa, M.D., Ph.D. (University of Tampere, Tampere University Hospital, Celiac Disease), Maria Lönnrot, M.D., Ph.D. (University of Tampere, Tampere University Hospital, Infectious Agents), Elina Mäntymäki (University of Turku, Turku University Hospital, Hospital District of Southwest Finland), Katja Multasuo (University of Oulu, Oulu University Hospital), Juha Mykkänen, Ph.D. (Turku University Hospital, Hospital District of Southwest Finland, University of Turku, Genetics), Tiina Niininen (Tampere University Hospital, University of Tampere, Study Coordinators), Mia Nyblom (University of Tampere, Tampere University Hospital), Petra Rajala (Turku University Hospital, Hospital District of Southwest Finland), Jenna Rautanen (Tampere University Hospital, National Institute for Health and Welfare, Finland), Anne Riikonen (University of Tampere, Tampere University Hospital), Minna Romo (University of Turku, Turku University Hospital, Hospital District of Southwest Finland), Satu Simell, M.D., Ph.D. (Turku University Hospital, Hospital District of Southwest Finland, Tampere University Hospital, Celiac Disease), Tuula Simell, Ph.D., Ville Simell (Turku University Hospital, Hospital District of Southwest Finland, University of Turku, Celiac Disease), Maija Sjöberg (University of Turku, Turku University Hospital, Hospital District of Southwest Finland, Study Coordinators, Clinical Implementation), Aino Stenius (University of Oulu, Oulu University Hospital, Study Coordinators), Eeva Varjonen (University of Turku, Turku University Hospital, Hospital District of Southwest Finland, Study Coordinators), Riitta Veijola, M.D., Ph.D. (University of Oulu, Oulu University Hospital, Clinical Implementation), Suvi M. Virtanen, M.D., Ph.D. (University of Tampere, Tampere University Hospital, National Institute for Health and Welfare, Finland, Diet), and Mari Åkerlund (University of Tampere, Tampere University Hospital, National Institute for Health and Welfare, Finland).

Sweden Clinical Center. Åke Lernmark, Ph.D., PI (Ancillary Studies, Genetics, Human Subjects/Publicity/Publications, Immune Markers, Infectious Agents, Maternal Studies, Quality Assurance, Steering, Quality Assurance Subcommittee on Data Quality), Daniel Agardh, M.D., Ph.D. (Celiac Disease), Carin Andrén Aronsson (Diet, Celiac Disease), Maria Ask, Jenny Bremer, Ulla-Marie Carlsson, and Corrado Cilio, Ph.D., M.D. (Immune Markers), Camilla Ekstrand and Emelie Ericson-Hallström (Diet), Lina Fransson, Thomas Gard, Joanna Gerardsson, Rasmus Håkansson, Monica Hansen, and Gertie Hansson (Study Coordinators), Susanne Hyberg, Fredrik Johansen, Berglind Jonasdottir, M.D., Linda Jonsson, and Helena Elding Larsson, M.D., Ph.D. (Infectious Agents, Clinical Implementation), Barbro Lernmark, Ph.D., Maria Månsson-Martinez, Maria Markan, Theodosia Massadakis, and Jessica Melin (Study Coordinators), Zeliha Mestan, Kobra Rahmati, Anita Ramelius, Falastin Salami, Monica Sedig Järvirova, Sara Sibthorpe, Birgitta Sjöberg, and
Ulrica Swartling, Ph.D. (Psychosocial, Study Coordinators), Erika Trulsson and Carina Törn, Ph.D. (Genetics, Quality Assurance Subcommittee on Data Quality), Anne Wallin and Åsa Wimar (Study Coordinators, Clinical Implementation), and Sofie Åberg. Lund University.

Washington Clinical Center. William A. Hagopian, M.D., Ph.D., PI (Ancillary Studies, Genetics, Human Subjects/Publicity/Publications, Immune Markers, Infectious Agents, Laboratory Implementation, Steering, Celiac Disease, Clinical Implementation), Xiang Yan, M.D., and Michael Killian (Infectious Agents, Laboratory Implementation, Study Coordinators, Celiac Disease), Claire Cowen Crouch (Study Coordinators, Clinical Implementation, Quality Assurance Subcommittee on Data Quality), Jennifer Skidmore (Diet), Stephen Ayres, Kayleen Dunson, Diana Heaney, Rachel Hervey, Corbin Johnson, Rachel Lyons, Arlene Meyer, Denise Mulenga, Emma Schulte, Elizabeth Scott, Joshua Stabbert, and John Willis. Pacific Northwest Diabetes Research Institute.

Pennsylvania Satellite Center. Dorothy Becker, M.D., Margaret Franciscus, and MaryEllen Dalmagro-Elias Smith (Diet), Ashi Daftary, M.D., Mary Beth Klein, and Chrystal Yates. Children's Hospital of Pittsburgh of UPMC.

Data Coordinating Center. Jeffrey P. Krischer, Ph.D., PI (Ancillary Studies, Human Subjects/Publicity/Publications, Immune Markers, Quality Assurance, Steering), Michael Abbondondolo, Sarah Austin-Gonzalez, and Rasheedah Brown (Study Coordinators, Quality Assurance Subcommittee on Data Quality), Brant Burkhardt, Ph.D. (Immune Markers, Infectious Agents), Martha Butterworth (Diet), David Cuthbertson, Christopher Eberhard, Steven Fiske (Psychosocial), Dena Garcia, Veena Gowda, David Hadley, Ph.D. (Genetics, Celiac Disease), Hye-Seung Lee, Ph.D. (Ancillary Studies, Diet, Celiac Disease, Quality Assurance Subcommittee on Data Quality), Shu Liu and Xiang Liu, Ph.D. (Diet, Psychosocial, Study Coordinators), Kristian Lynch, Ph.D. (Immune Markers, Infectious Agents, Psychosocial, Quality Assurance Subcommittee on Data Quality), Jamie Malloy and Cristina McCarthy (Study Coordinators, Quality Assurance Subcommittee on Data Quality), Wendy McLeod (Diet, Immune Markers, Infectious Agents, Celiac Disease, Quality Assurance Subcommittee on Data Quality), Chris Shaffer and Laura Smith, Ph.D. (Psychosocial, Study Coordinators), Susan Smith (Study Coordinators, Quality Assurance Subcommittee on Data Quality), Roy Tamura, Ph.D. (Ancillary Studies, Diet, Celiac Disease), Ulla Uusitalo, Ph.D. (Diet, Quality Assurance Subcommittee on Data Quality), Kendra Vehik, Ph.D. (Human Subjects/Publicity/Publications, Immune Markers, Infectious Agents, Clinical Implementation, Quality Assurance Subcommittee on Data Quality), and Ponni Vijayakandipan, Keith Wood, and Jimin Yang, Ph.D., R.D. (Diet, Quality Assurance Subcommittee on Data Quality). University of South Florida.

Project Scientist. Beena Akolkar, Ph.D. (Ancillary Studies, Genetics, Human Subjects/Publicity/Publications, Immune 
Markers, Infectious Agents, Laboratory Implementation, Quality Assurance, Steering). National Institutes of Diabetes and Digestive and Kidney Diseases.

Other Contributors. Kasia Bourcier, Ph.D. (Immune Markers), National Institutes of Allergy and Infectious Diseases. Thomas Briese, Ph.D. (Infectious Agents, Quality Assurance Subcommittee on Data Quality), Columbia University. Suzanne Bennett Johnson, Ph.D. (Psychosocial, Study Coordinators), Florida State University. Steve Oberste, Ph.D. (Infectious Agents), Centers for Disease Control and Prevention. Eric Triplett, Ph.D. (Infectious Agents), University of Florida.

Autoantibody Reference Laboratories. Liping Yu, M.D. (Barbara Davis Center for Childhood Diabetes, University of Colorado Denver, Immune Markers), Dongmei Miao, M.D. (Barbara Davis Center for Childhood Diabetes, University of Colorado Denver), Polly Bingley, M.D., FRCP (School of Clinical Sciences, University of Bristol, UK, Immune Markers), Alistair Williams (School of Clinical Sciences, University of Bristol, UK), Kyla Chandler (School of Clinical Sciences, University of Bristol, UK), Saba Rokni (School of Clinical Sciences, University of Bristol, UK), Joanna Boldison (School of Clinical Sciences, University of Bristol, UK), Jacob Butterly (School of Clinical Sciences, University of Bristol, UK), Gabriella Carreno (School of Clinical Sciences, University of Bristol, UK), Claire Caygill (School of Clinical Sciences, University of Bristol, UK), Ivey Geoghan (School of Clinical Sciences, University of Bristol, UK), Anna Long (School of Clinical Sciences, University of Bristol, UK), Molly Payne (School of Clinical Sciences, University of Bristol, UK), James Pearson (School of Clinical Sciences, University of Bristol, UK), Sophie Ridewood (School of Clinical Sciences, University of Bristol, UK), and Rebecca Wyatt (School of Clinical Sciences, University of Bristol, UK).

Cortisol Laboratory. Elisabeth Aardal Eriksson, M.D., Ph.D., Ing-Marie Lundgren, Ewa Lönn Karlsson, Dzeneta Nezirevic Dernroth, Ph.D. Department of Clinical Chemistry, Linköping University Hospital, Linköping, Sweden.

Dietary Biomarkers Laboratory. Iris Erlund, Ph.D. (Diet), Irma Salminen, Jouko Sundvall, Jaana Leiviskä, and Mari Lehtonen, Ph.D. National Institute for Health and Welfare, Helsinki, Finland.

HbA1c Laboratory. Randie R. Little, Ph.D., Alethea L. Tennill. Diabetes Diagnostic Laboratory, Department of Pathology, University of Missouri School of Medicine.

HLA Reference Laboratory. Henry Erlich, Ph.D. (Genetics), Steven J. Mack, Ph.D., Anna Lisa Fear. Center for Genetics, Children's Hospital Oakland Research Institute.

Metabolomics Laboratory. Oliver Fiehn, Ph.D., Bill Wikoff, Ph.D., Brian Defelice, Dmitry Grapov, Ph.D., Tobias Kind, Ph.D., Mine Palazoglu, Luis Valdiviez, Benjamin Wancewicz, Gert Wohlgemuth, and Joyce Wong. UC Davis Metabolomics Center.
Microbiome and Viral Metagenomics Laboratory. Joseph F. Petrosino, Ph.D. (Infectious Agents). Alkek Center for Metagenomics and Microbiome Research, Department of Molecular Virology and Microbiology, Baylor College of Medicine.

OGTT Laboratory. Santica M. Marcovina, Ph.D., Sc.D., Vinod P. Gaur, Ph.D., Northwest Lipid Metabolism and Diabetes Research Laboratories, University of Washington.

Proteomics Laboratory. Richard D. Smith, Ph.D., Thomas O. Metz, Ph.D., Charles Ansong, Ph.D., Bobbie-Jo WebbRobertson, Ph.D., and Hugh D. Mitchell, Ph.D. Pacific Northwest National Laboratory.

Repository. Heather Higgins and Sandra Ke. NIDDK Biosample Repository at Fisher BioServices.

RNA Laboratory and Gene Expression Laboratory. JinXiong She, Ph.D., PI (Ancillary Studies, Genetics, Human Subjects/Publicity/Publications, Steering), Richard McIndoe, Ph.D., Haitao Liu, M.D., John Nechtman, Yansheng Zhao, Na Jiang, M.D. Jinfiniti Biosciences, LLC.

SNP Laboratory. Stephen S. Rich, Ph.D. (Genetics), WeiMin Chen, Ph.D. (Genetics), Suna Onengut-Gumuscu, Ph.D. (Genetics), Emily Farber, Rebecca Roche Pickin, Ph.D., Jordan Davis, Dan Gallo, Jessica Bonnie, and Paul Campolieto. Center for Public Health Genomics, University of Virginia.

\section{Conflict of Interests}

The authors declare that there is no conflict of interests regarding the publication of this paper.

\section{Acknowledgments}

The TEDDY Study Group (see Appendix) is funded by U01 DK63829, U01 DK63861, U01 DK63821, U01 DK63865, U01 DK63863, U01 DK63836, U01 DK63790, UC4 DK63829, UC4 DK63861, UC4 DK63821, UC4 DK63865, UC4 DK63863, UC4 DK63836, UC4 DK95300, and UC4 DK100238 and by Contract no. HHSN267200700014C from the National Institute of Diabetes and Digestive and Kidney Diseases (NIDDK), National Institute of Allergy and Infectious Diseases (NIAID), National Institute of Child Health and Human Development (NICHD), National Institute of Environmental Health Sciences (NIEHS), Juvenile Diabetes Research Foundation (JDRF), and Centers for Disease Control and Prevention (CDC). This work was supported in part by the NIH/NCATS Clinical and Translational Science Awards to the University of Florida (UL1 TR000064) and the University of Colorado (UL1 TR001082).

\section{References}

[1] The TEDDY Study Group, "The Environmental Determinants of Diabetes in the Young (TEDDY) study: study design," Pediatric Diabetes, vol. 8, no. 5, pp. 286-298, 2007.

[2] C. W. Karlson and M. A. Rapoff, "Attrition in randomized controlled trials for pediatric chronic conditions," Journal of Pediatric Psychology, vol. 34, no. 7, pp. 782-793, 2009. 
[3] A. M. Butz, J. S. Halterman, M. Bellin et al., "Factors associated with completion of a behavioral intervention for caregivers of urban children with asthma," Journal of Asthma, vol. 49, no. 9, pp. 977-988, 2012.

[4] K. A. Driscoll, M. Killian, S. B. Johnson, J. H. Silverstein, and L. C. Deeb, "Predictors of study completion and withdrawal in a randomized clinical trial of a pediatric diabetes adherence intervention," Contemporary Clinical Trials, vol. 30, no. 3, pp. 212-220, 2009.

[5] N. A. Williams, M. Coday, G. Somes, F. A. Tylavsky, P. A. Richey, and M. Hare, "Risk factors for poor attendance in a family-based pediatric obesity intervention program for young children," Journal of Developmental and Behavioral Pediatrics, vol. 31, no. 9, pp. 705-712, 2010.

[6] M. Zeller, S. Kirk, R. Claytor et al., "Predictors of attrition from a pediatric weight management program," Journal of Pediatrics, vol. 144, no. 4, pp. 466-470, 2004.

[7] G. Helgesson, M. G. Hansson, J. Ludvigsson, and U. Swartling, "Practical matters, rather than lack of trust, motivate nonparticipation in a long-term cohort trial," Pediatric Diabetes, vol. 10, no. 6, pp. 408-412, 2009.

[8] B. Lernmark, S. B. Johnson, K. Vehik et al., "Enrollment experiences in a pediatric longitudinal observational study: The Environmental Determinants of Diabetes in the Young (TEDDY) study," Contemporary Clinical Trials, vol. 32, no. 4, pp. 517-523, 2011.

[9] S. B. Johnson, H. S. Lee, J. Baxter, B. Lernmark, R. Roth, and T. Simell, "The Environmental Determinants of Diabetes in the Young (TEDDY) Study: predictors of early study withdrawal among participants with no family history of type 1 diabetes," Pediatric Diabetes, vol. 12, pp. 165-171, 2011.

[10] S. B. Johnson, K. F. Lynch, H.-S. Lee et al., "At high risk for early withdrawal: Using a cumulative risk model to increase retention in the first year of the TEDDY study," Journal of Clinical Epidemiology, vol. 67, no. 6, pp. 609-611, 2014.

[11] W. A. Hagopian, H. Erlich, Å. Lernmark et al., "The Environmental Determinants of Diabetes in the Young (TEDDY) Study: genetic criteria and international diabetes risk screening of 421,000 infants," Pediatric Diabetes, vol. 12, no. 8, pp. 733-743, 2011.

[12] C. D. Spielberger, R. I. Gorsuch, and R. Lushene, Test Manual for the State-Trait Anxiety Inventory, Consulting Psychologists Press, Palo Alto, Calif, USA, 1970.

[13] C. Bradley, “The Weill-Being questionnaire," in Handbook of Psychology and Diabetes, C. Bradley, Ed., pp. 89-109, Hardwood Academic Publishers, 1994.

[14] T. Piira, G. D. Champion, T. Bustos, N. Donnelly, and K. Lui, "Factors associated with infant pain response following an immunization injection," Early Human Development, vol. 83, no. 5, pp. 319-326, 2007.

[15] S. Evans, L. C. Seidman, K. Lung, L. K. Zeltzer, and J. C. Tsao, "Sex differences in the relationship between maternal fear of pain and children's conditioned pain modulation," Journal of Pain Research, vol. 6, pp. 231-238, 2013.

[16] B. Lernmark, K. Lynch, L. Ballard et al., "Reasons for staying as a participant in the environmental determinants if diabetes in the young (TEDDY) longitudinal study," Journal of Clinical Trials, vol. 2, article 2, 2012. 


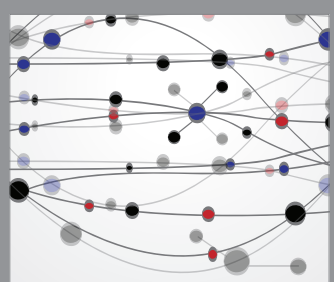

The Scientific World Journal
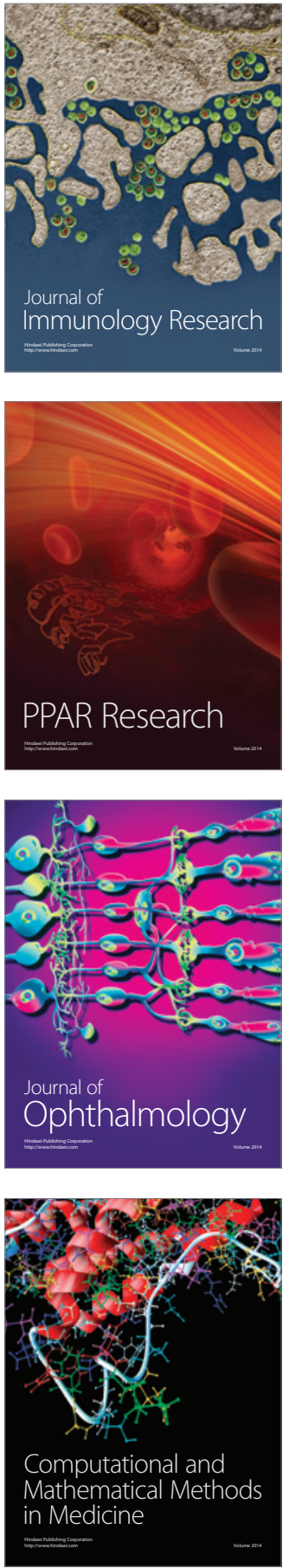

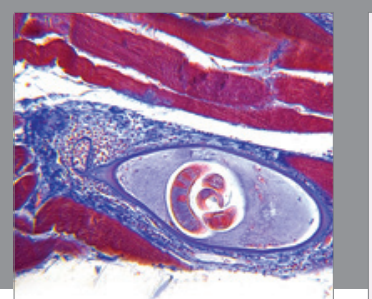

Gastroenterology Research and Practice

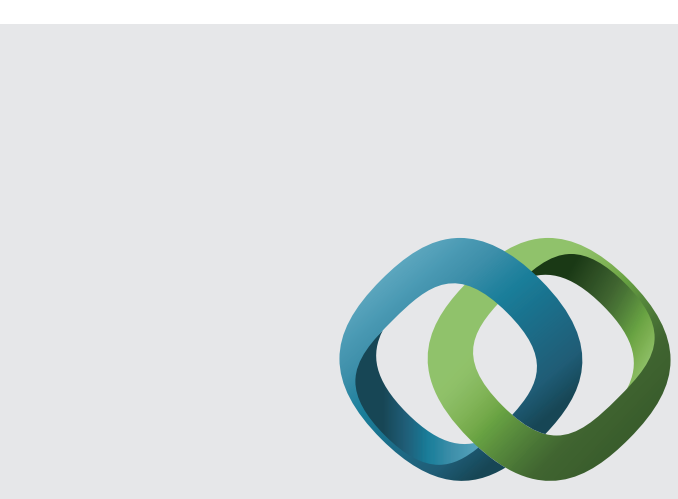

\section{Hindawi}

Submit your manuscripts at

http://www.hindawi.com
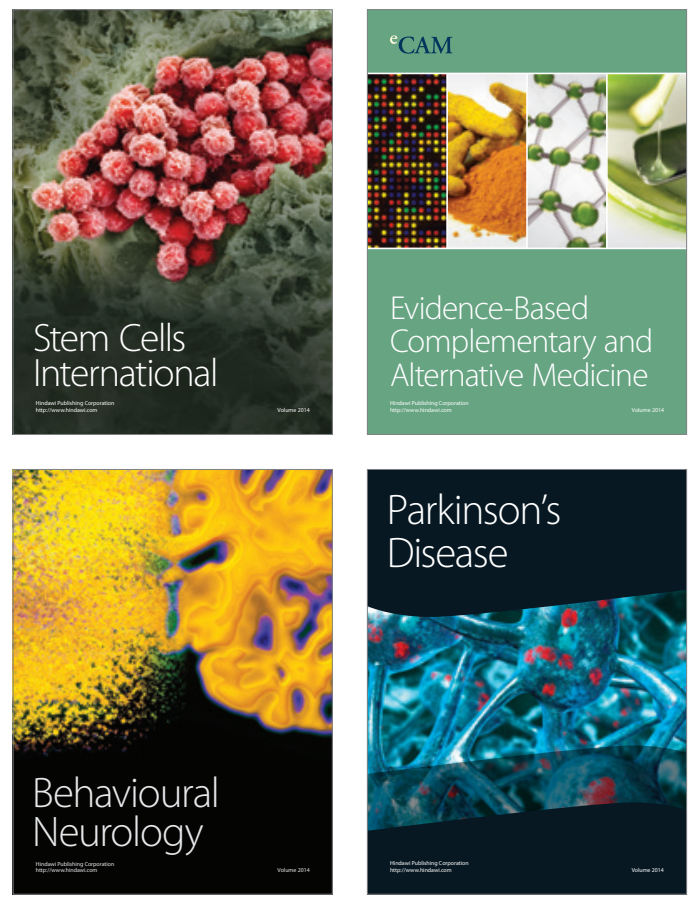
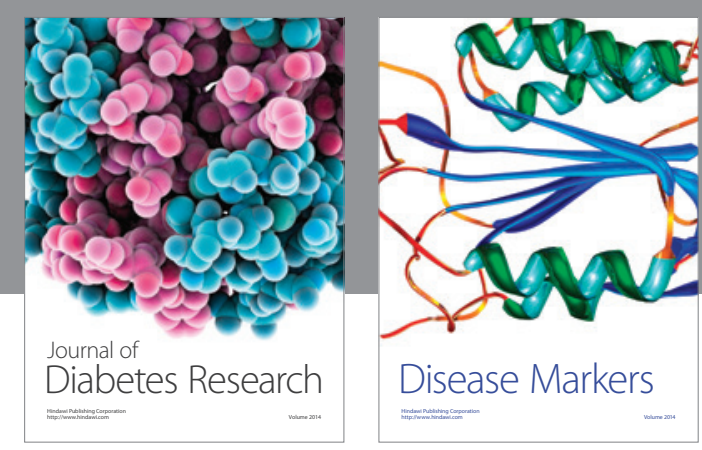

Disease Markers
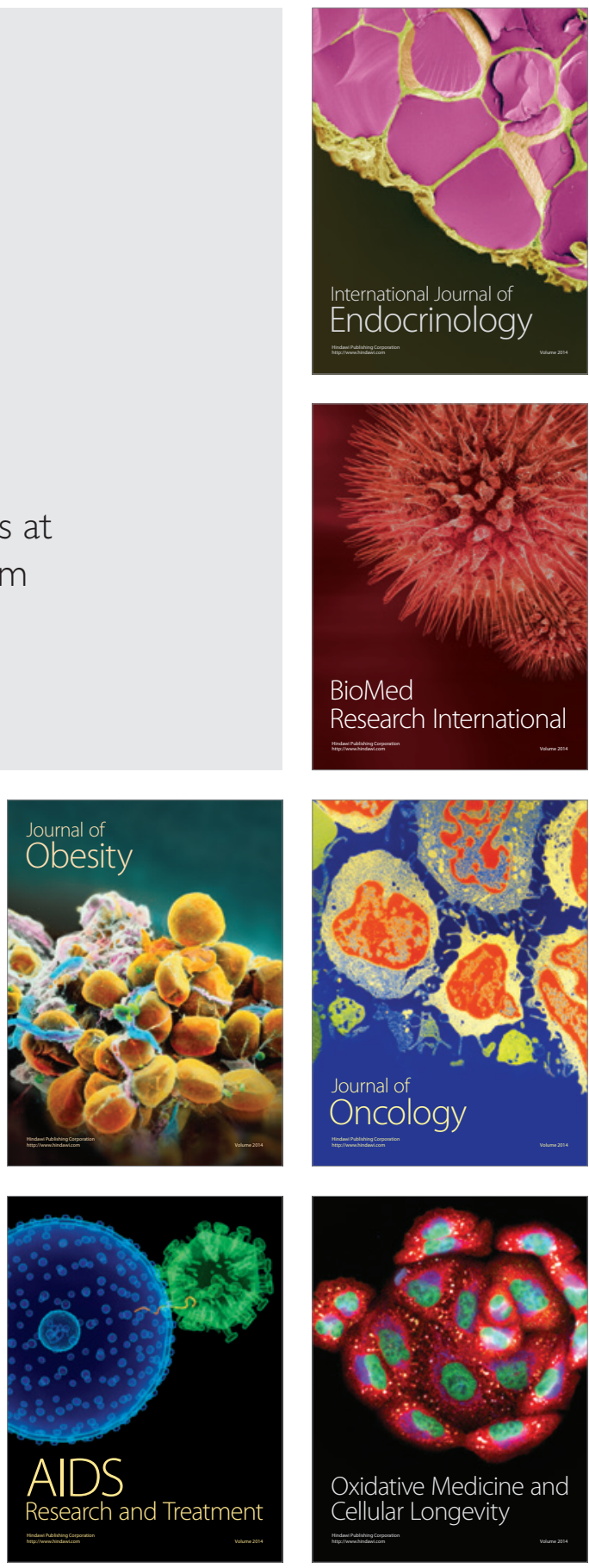